\title{
It Is Time for the Violence and Gender Journal
}

\author{
Mary Ellen O'Toole, PhD
}

I AM TRULY EXCITED AND HONORED to be Editor-inChief of Violence and Gender in a time when shocking events such as Columbine, Sandy Hook, and the Boston Marathon have caused us all to pause and ponder the very nature of our fellow human being.

Reviews of these tragedies indicate that the perpetrators are predominantly male. Furthermore, we see incidents such as rape, spousal abuse, and other acts of social violence perpetrated primarily by males. Certainly, females are not immune to such acts, but the acts of females tend to be quite different from those perpetrated by males. Why is that? Are root causes of these differences to be found in biology, physiology, psychology, diet and nutrition, or the games these perpetrators play? This powerful, groundbreaking, peerreviewed journal is dedicated to investigating the gender differences that manifest into varied expressions of violent behaviors.

The study of violence has been my profession for more than 30 years. As an FBI agent and FBI "profiler" I have investigated violence, studied it, analyzed it, and written and taught about it. But I have never before seen a focus on the role of gender in the causation, manifestation, commission, and prevention of violent behavior.

The mission of Violence and Gender is to identify and critically analyze biological, cultural, psychological, social, spiritual, anthropological, and environmental factors that influence males and even females to act violently. Are males, in fact, more violent than females? Do both sexes act out violently but in different ways? Are there different influencing factors that impact violent behavior for each sex? Violence and Gender will explore these questions and more by confronting controversial, even unsettling issues to determine the complex relationship between gender and violence.

Violence is complicated and too often misunderstood, myth-based, and stereotyped. We are shocked when we see the "nice guy" next door arrested for serial murder, or when the quiet loner goes on a shooting rampage. Many of us even default to using terms like "monster" and "evil" to explain such behavior and the people responsible. These archaic terms don't educate us or explain the violence but rather catapult us back into the $14^{\text {th }}$ century when werewolves and vampires were blamed for acts of violence.

In the wake of September 11, and the event in Norway when Anders Breivik shot and killed 77 people, and more recently at the theater shooting in Aurora, Colorado, as well as the tragedy at Sandy Hook Elementary School in New- town, Connecticut, and the bombings at the Boston Marathon, there has been an outcry for explanations as to why young males act so violently.

In light of these events and the resulting controversies, Mary Ann Liebert, president and CEO of Mary Ann Liebert, Inc., publishers, decided it is time to take on these critical questions about gender and violence. As a result of Mary Ann's insight and vision, Violence and Gender was created. Her goal of a journal that will be provocative, educational, and extremely insightful will be realized through her diverse staff of assistants, editors, experts, contributors, and readers.

What will allow Violence and Gender to make an even more profound contribution to our understanding of genderbased violence is our partnership with The Avielle Foundation, an amazing foundation created in memory of a little six-year-old girl, Avielle Rose, who inspires us all. The Avielle Foundation, created after the tragedy in Newtown, Connecticut, has a mission to prevent violence by fostering brain health research, education, and policy; community development, engagement, and responsibility.

When I first met Jen and Jeremy Richman, Avielle's parents and the founders of The Avielle Foundation, I realized the unique synergy between Violence and Gender and their foundation's goals. This extraordinary partnership will allow us to finally bridge the research gaps between the biochemical and genetic sciences and the behavioral, psychological, cultural, and social sciences to find those answers we are all seeking.

I know violence is a complex and complicated issue and there are no easy fixes and no easy answers, but I believe that now is the time to bring together the powerful, collective expertise from all these sciences and apply that collaborative knowledge to identifying causes, contributors, and solutions to this brutal and gratuitous violence our society has never before seen, and to provide reasons for the gender differences in the manifestation of this violence.

On behalf of all of us associated with Violence and Gender, we promise to bring you the most responsible, current, and thoughtful research articles, case studies, and discussions about violence and gender. We will publish scientific truth versus fiction and investigate contributing factors, prediction, and intervention of violent events.

We invite you to be a partner in this effort to understand and prevent violent behavior through your subscriptions, feedback, review of manuscripts, and submittal of your own

Senior FBI Profiler/Criminal Investigative Analyst (ret.), Behavioral Analysis Unit. 
original research articles, case studies, opinions, and letters to the editor.

We should never experience another tragedy like what we saw at Aurora, Colorado, Columbine High School, Utoya, Norway or Sandy Hook Elementary School - and we don't have to. Our mission, with your support, to identify, predict, and prevent this type of violence is realistic and achievable. And now with the scientific expertise to do the work and Violence and Gender to report about it I know we are going to make a difference. Ladies and gentlemen, we have no other choice. This is no longer someone else's tragedy. It is ours. And we as scientists, educators, law enforcement, mental health professionals, legislators, clergy, parents, students and others must fix it.

The time is now. The place is Violence and Gender.

\section{Disclaimer}

The views of Dr. Mary Ellen O'Toole do not represent the views of the FBI.

Address correspondence to: Mary Ellen O'Toole, PhD

E-mail: violenceandgender@liebertpub.com 